\title{
Preservice Teacher Perspectives on Learning with Technology: Modeling Vulnerability and Embracing Innovation
}

\author{
Rebecca Smith \\ University of Portland
}

\begin{abstract}
This study examined preservice teacher perspectives on the impact of using untethered lecture capture (ULC) as an instructional technology in a teacher preparation course, exploring both their learning experiences as students and confidence using technology as teachers. Results found statistically significant $(p<$ .05) increases in confidence using technology as a teaching tool. Additionally, Darling-Hammond et al.'s (2018) Teacher Preparation for Deeper Learning framework was utilized to explore the impact of ULC on preservice teacher learning. Challenges and recommendations for effective implementation of ULC, based on participant feedback, are provided. This study contributes to research on using technology in teacher preparation programs to enhance the teaching and learning process for preservice educators and is grounded in the TPACK model (Mishra \& Koehler, 2009).
\end{abstract}

Keywords: instructional technology, preservice teachers, lecture capture

Technology continues to evolve, and teachers must be prepared for digital classrooms. The COVID-19 pandemic impacted approximately 1.6 billion learners in 200 countries around the world, shifting learning online across the globe (Pokhrel \& Chhetri, 2021). The emerging post-COVID educational landscape appears to be retaining online or blended learning options, embracing e-learning as the "new normal" (Pham \& Ho, 2020, p. 1327). The increase of virtual learning platforms from K-12 through college depends on teacher preparation programs to enhance teacher capacity to teach with technology.

The majority of students in teacher preparation programs today are part of iGen, a technology-from-birth generation of students born after 1995. Yet, limited research on the impact of this technological exposure suggests great disparities in digital competence (Li \& Ranieri, 2010). Additionally, the literature suggests that teachers may not be integrating technology effectively and efficiently into their practice, which can also adversely impact the technological preparation of P-12 students (An \& Reigeluth, 2011; Hammonds et al., 2013). Further, many teacher preparation programs contain a stand-alone 
technology course that lacks an infusion of technology into curriculum and methods needed for adequate application (Foulger et al., 2019). Personal and institutional barriers can also impede effective technology use, such as a lack of confidence or competence with technology, anxiety when implementing new technologies in front of students, and time needed for professional development to support teachers (Aldunate \& Nussbaum, 2013; Kim et al., 2013; Kurt, 2013).

\section{Literature Review}

\section{Teacher Readiness for Teaching with Technology}

Readiness to teach online or in blended environments depends on numerous factors. Higher education teachers from 58 countries $(N=739)$ who were forced to transition to online teaching and learning due to the COVID-19 pandemic were found to have varying degrees of readiness to teach online (Scherer et al., 2021). Numerous factors impacted readiness, including gender, prior online teaching and learning experience, context of the shift to online instruction. Additionally, a blended approach to teaching, such as teaching both virtually and face-to-face, can place substantial demands on the teacher, both in the preparation of resources, and in the capacity to manage multiple learning spaces (Bower et al., 2017). Providing training and professional development for in-service teachers can help increase efficacy in teaching online (Philipsen et al., 2019).

The lack of tech-savvy teachers is compounded by research indicating that teacher preparation programs lack of integration of technology into lesson planning and knowledge of technology standards (Alger \& Kopcha, 2009; Chesley \& Jordan, 2012; Mishra \& Koehler, 2006). We must focus on preparing teachers with 21 st century skills, which include competence with technology, critical thinking, cultural sensitivity, and dealing with diversity; we also need teachers who can expose students from all income levels to innovative forms of technology (Adams Becker et al., 2016). The International Society for Technology in Education (ISTE, 2020) standards for educators call for teachers to be learners who engage with others to explore "proven and promising" technology practices, collaborate with others to share resources and solve problems, and also to support student learning through the use of technology.

\section{Lecture Capture}

One such potential promising technological pedagogical method is Untethered Lecture Capture (ULC), which entails using an iPad to project lecture notes onto a large screen for students to view, while simultaneously allowing the instructor to walk around the room annotating the lecture slides with a stylist pen to add notes to the slides. ULC also allows the instructor to "capture" the lecture and make an audio recording of the edited slide presentation and course discussions, which can then be uploaded online for student viewing after class. ULC allows the instructor to take pictures of student or group work; record student voices; and draw, write, and edit material in real time. These artifacts then become an embedded part of the lecture for students to revisit. The use 
of lecture capture is not new, and yet the use of an iPad to record synchronous learning activities, in addition to scaffolding preservice teacher instruction with this technology, provides a unique perspective for supporting the integration of pedagogical, technological, and content knowledge for teacher learning.

There is a dearth of research on how untethered lecture capture can be used as a tool to prepare preservice teacher educators for technology-infused classrooms. The limited research on ULC indicates positive impacts on student access to content learning and increases in student-teacher interactions during class (Krautscheid et al., 2019). The purpose of this study was to therefore explore this research gap. More specifically, this study asked: (1) What is the impact of using Untethered Lecture Capture (ULC) on undergraduate preservice teacher candidates, both on their learning experience as students and in their confidence using technology as teachers? (2) To what extent does ULC have the potential to deepen student learning, as understood by Darling-Hammond et al.'s (2019) Teacher Preparation for Deeper Learning framework?

In addition to applying Darling-Hammond's (2019) Deeper Learning Framework to this research, this study was also informed by Technological Pedagogical Content Knowledge (TPACK) (Koehler \& Mishra, 2009; Mishra \& Koehler, 2006). The TPACK model has become a common framework in research surrounding teacher preparation and technology (see Figure 1). TPACK integrates teacher knowledge of content, pedagogy, and technology, and argues that teachers must have a working understanding of each of these concepts in order to effectively integrate technology into teaching practice. The use of TPACK in relationship to teacher preparation "emphasizes technology integration be addressed within the context of the content being taught" (Foulger et al., 2019). In one study (Wetzel et al., 2014), when preservice teachers were explicitly taught about the TPACK model in education courses, they appreciated understanding how this framework applied to teaching and learning with technology. Further research on the use of TPACK within teacher preparation (Papanikolaou, 2017) argues for a constructivist approach to teaching technology, viewing teachers as "designers of innovative content, working individually and/or collaboratively, discussing and interacting with the instructor, technology and their peers" (p. 1). This study will explore how ULC integrates a TPACK model into teacher preparation. 


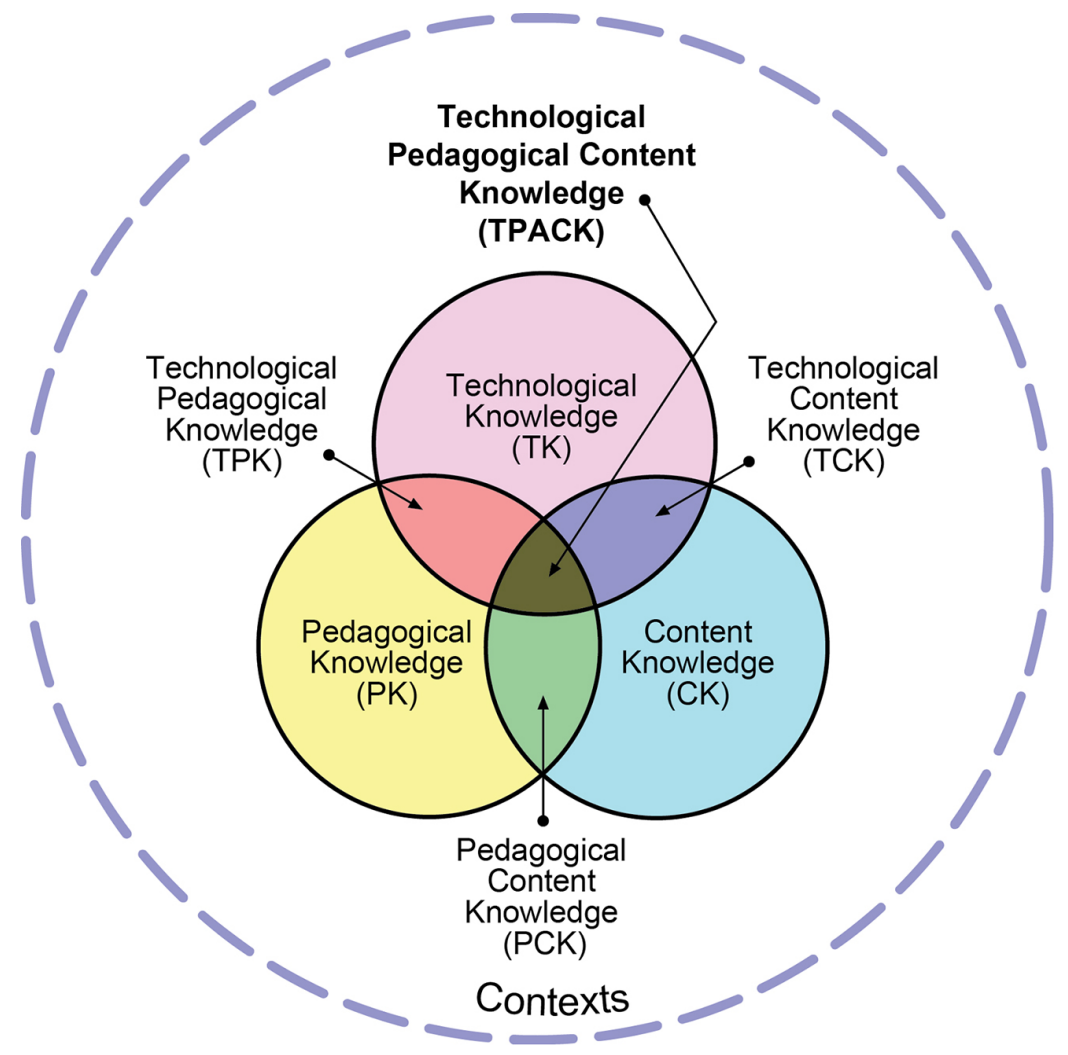

Figure 1. TPACK Model

\section{Methods}

This mixed methods study investigating the impact of ULC occurred at a small liberal arts university in the Pacific Northwest in a one-semester Curriculum and Instruction course. Participants included 18 preservice teacher candidates. The entire class $(n=18)$ self-identified as female and $56 \%$ self-identified as White, $22 \%$ as bi-racial, $11 \%$ as Hispanic/Latino, $6 \%$ as Filipino, and 6\% preferred not to answer. Despite the small sample size, the inclusion of multiple forms of data allowed for triangulation, and this research further contributes to the literature on interactive instructional technologies, especially surrounding the teaching and learning process in teacher preparation.

At the beginning of the course, the teacher educator provided an overview of ULC for students, demonstrating the new technology and explaining that she would also be learning the technology alongside the students. ULC was then used as the main instructional technology by the teacher educator in the three-hour, once per week class for approximately 14 weeks. This instructional strategy, as mentioned previously, entailed using an iPad during face-to-face instruction, in addition to recording the class and posting it as a video lecture for students to view after class if desired. The instructor prepared a Power Point presentation, which was saved as a PDF and uploaded to the application Explain Everything. This app allows the user to project the presentation for students to view on a large screen and allows for live annotation on the iPad with a stylist pen. The verbal class was also captured through the use of recording capability on Explain Every- 
thing and later uploaded as a video lecture to the class Learning Management System. Additionally, all the students were required to create a lesson plan and teach their peers a K-12 lesson simulation using the ULC technology. Preservice teacher learning around the ULC technology was scaffolded through explicit modeling and providing students with opportunities to practice with the technology prior to their own instructional lesson.

\section{Data Sources}

This study included quantitative and qualitative data collection from multiple sources in order to triangulate the findings, improving quality and confirmability (Miles et al., 2014). First, all preservice teacher participants completed a pre- and post-survey; the survey questions featured rating scale items and open-ended questions, which were modified from two prior studies on similar instructional technologies (Gosper et al., 2010; Marchand et al., 2014). Sample survey items included: Using ULC as a student made learning easier; It is important that students attend class even if ULC is available; ULC allowed me to review complex ideas and concepts. The survey items entailed multiple rounds of iterative feedback for revision and use in this study (Dillman et al., 2009). Second, following the course-long implementation of ULC, students completed an open-ended reflective essay in response to a few guiding questions, such as Please summarize your experience using ULC as a teacher in a student-led presentation. Third, data analytics on ULC participant usage were also collected to identify the number of hours student participants spent viewing captured lectures outside of class. Data analytics helped to measure the fidelity of implementation.

\section{Data Analysis}

The quantitative pre-post survey data were analyzed using a paired samples t-test and descriptive statistics. The qualitative data were analyzed utilizing a framework for Teacher Preparation for Deeper Learning (TPDL) (Darling-Hammond et al., 2018). A priori, or prefigured coding (Creswell, 2013), was chosen as the method of analysis in order to gain a clear understanding of the potential impact of ULC on teachers' deeper learning. The recommendations were informed by qualitative data that were coded loosely with pattern coding to identify categories, themes, and relationships (Miles et al., 2014).

\section{Quantitative Results}

The quantitative data were analyzed using descriptive statistics. Table 1 contains the percentage growth gains from pre- to post-survey on each survey item. All 15 survey items showed positive growth from pre- to post-survey, with the strongest post-survey agreement being in the question about confidence using technology as a student $(100 \%$ post agreement) and about ULC allowing students to work at their own pace (94\% post agreement). The results are summarized into three main themes below regarding the impact of ULC on preservice teacher educators. Data analytics revealed a total user participant viewing time of course content outside of class, captured by the ULC tool at 891 minutes ( 15 hours). 
Table 1. Post-ULC Survey Results Per Item ( $n=18)$

\section{Agree PRE Agree POST}

Percent Percent Change

1. I feel confident about using technology as a student for learning.

$78 \%$

$100 \%$

$+22 \%$ *

2. I feel confident about using technology as a teaching tool.

$67 \%$

$88 \%$

$+21 \%$ *

3. Using ULC as a student made learning easier.

$83 \%$

4. Using ULC helped me achieve better academic results.

5. It is important that students attend class even if ULC is available.

6. It is possible to learn as well from recordings as from face-to-face classes.

7. ULC allowed me to review items I missed during the class.

8. ULC allowed me to prepare for course assessments or exams.

9. ULC allowed me to review course content when I was absent from class.

10. ULC allowed me to review complex ideas and concepts.

11. ULC allowed me to work at my own pace.

12. ULC allowed me to take comprehensive notes.

13. ULC allowed me to review course announcements.

14. ULC allowed me to revisit material because the lecturer did not speak clearly.

15. ULC allowed me to revisit material because English is not my first language. 


\section{Increased confidence}

Several key results emerged in the quantitative data analysis. First, it appears that using ULC as an instructional tool has the potential to help prepare preservice teachers to be more confident in using technology as teachers. A paired samples $t$-test from pre- to post-intervention revealed statistically significant growth for the item How do you feel about using technology as a teaching tool on a scale of 1 (not confident at all) to 4 (completely confident) from pre $(M=2.76, S D=.66)$ to post $(M=3.12, S D=.60 ; p=.029)$. Additionally, the survey item How do you feel about using technology as a student for learning also showed positive gains $(p=.056)$ from pre- to post-test.

\section{Improved Learning Experience}

In addition to confidence increases in technology use as both students and teachers, ULC also appeared to positively impact student learning. On the survey item Using ULC as a student made learning easier, $83 \%$ of participants agreed. Also, in response to the survey item ULC allowed me to review items I missed during the class, $89 \%$ agreed. Furthermore, $94 \%$ of participants agreed with the item ULC allowed me to work at my own pace. These data indicate the positive and individualized impact on student learning with the use of ULC.

\section{Differentiation}

The use of ULC also appeared to benefit students beyond the walls of the classroom, especially in regard to absenteeism. For the item ULC allowed me to review course content when I was absent from class, $89 \%$ of participants agreed, and $83 \%$ agreed that ULC allowed them to review complex ideas and concepts. Despite the benefits of ULC when students are absent, participant data indicated that students still valued face-toface learning. For instance, $89 \%$ of students agreed that It is important that students attend class even if ULC is available. In agreement with this finding, only $33 \%$ of participants agreed It is possible to learn as well from recordings as from face-to-face classes. These findings suggest that ULC is able to accommodate and differentiate for the needs of students, especially if they are unable to attend class, and yet, students still believe attending in-person classes is a valuable learning experience.

\section{Qualitative Results}

The qualitative data gathered in reflective exit essays were deductively coded using a priori, or prefigured coding (Creswell, 2013). The codes were based on a framework of Teacher Preparation for Deeper Learning (TPDL) (Darling-Hammond et al., 2018). According to Darling-Hammond et al. (2018), "Deeper learning encompasses learning that is inquiry-based, collaborative, focuses on mastery of content, communication, critical thinking, and sense making" (p. 1). The original (2018) framework contains four key domains, including: 1) learning that is developmentally grounded and personalized; 2) learning in productive communities of practice; 3 ) learning that is contextualized; and 4) 
learning that is equitable and social justice oriented. These domains will be described more in detail below. The more recent book on deeper learning (Darling-Hammond et al., 2019) provides an additional domain: learning that is applied and transferred. This data analysis occurred prior to the publication of this fifth domain, so it was excluded from the analysis.

\section{Learning That Is Developmentally Grounded and Personalized}

The first domain of the TPDL framework (Darling-Hammond et al., 2018) focuses on how learning experiences build on prior knowledge and experience, and account for learners' active construction of new knowledge. Learning connects to who students are as well as what they already know, attending to both cognitive and socio-emotional realms. The qualitative data revealed both the challenges and successes of learning a new technology, allowing students to build on previous confidence and experience with technology. For instance, one participant stated:

Although this is a new concept for me, I am excited to see what the future holds for this tool because, like most educators, I am eager to learn and willing to try any tool that will best help my future students.

Learning a new technology as a preservice teacher within the university course, rather than learning 'on the job' as a new teacher, appeared to deepen the learning experience. For instance, another participant stated, "I found that this class allowed me to try out the skills and new knowledge from other classes, and I greatly appreciated being able to do that in a safe space, especially in regards to ULC."

Preservice teacher participants also appeared to engage in reflective practice, constructing new knowledge by listening to their own captured lecture. This reflective practice helped to personalize scaffolded learning over time. Participants highlighted the desire to be better teachers and to grow in their practice as new teachers. ULC provided an opportunity to analyze their actual teaching practice in a non-threatening environment and a platform that they could access on their own time.

\section{Learning In Productive Communities of Practice}

The second domain of the TPDL framework (Darling-Hammond et al., 2018) focuses on learning as an active, interactive, constructive, and iterative process. School and classroom communities are built on an ethic of caring, offering supports for social/emotional development, trusting relationships, and restorative practices to create suitable environments for student learning.

The use of ULC in the classroom appeared to promote collaborative learning experiences among student learners. Numerous qualitative comments highlighted the interactive nature of ULC between students, with the teacher, and with the technology itself. For instance, one participant stated, "It also allows for writing on the slides and highlighting on the slides and can be very useful for the engagement of student-centered learning." 
Further, one participant identified the ability of ULC to promote teacher-student relationships as well, "I think ULC is a useful tool for providing student-teacher interaction even outside of the classroom."

Furthermore, the data indicate that ULC promotes an interactive and engaging space for learning. According to one participant:

I find the ULC virtual lecture to be far more engaging than a video of a professor talking at me. The layering of audio and visuals made it really interactive, and I love that it's archived, too. This way, I can go back to it and re-watch missed parts or pause the video at parts that I need to review.

Another participant said, "I love using technology as a student. It allows me to not exhaust myself writing notes, and I can create visuals to help me remember things." In addition to the benefits regarding content learning, another participant mentioned the ability to engage with the class when they were the teacher (i.e., in a student-led presentation):

I enjoyed being able to adapt my presentation as I went, add drawings, voice record, and post pictures directly into the presentation. I could walk around the room with ULC and engage with students more closely while also having a device on hand.

The freedom that ULC enabled in the classroom appeared to enhance and deepen learning for students.

\section{Learning That Is Contextualized}

The third domain of the TPDL framework (Darling-Hammond et al., 2018) focuses on how learning experiences are created with the recognition that people develop as they use the tools and symbols of their cultural contexts to make sense of the world and their experiences in it. Learning builds on students' personal, cultural, and linguistic knowledge, and is embedded in meaningful contexts and applications.

The data coded into this domain fell mostly in students' conceptualization of themselves in the context of future educators. The results of the qualitative data analysis revealed that participants appreciated using ULC as students, and yet using ULC as a future teacher seemed unlikely for many of them. Several participants believed that ULC was better suited for older students and not well adapted for elementary education. This inability to envision the integration an innovative technology at the elementary level indicates a lack of deeper learning with these preservice teacher educators. Perhaps this finding is also a limitation of ULC itself. The use of modeling through video recording of ULC within an elementary educational context could greatly benefit these preservice educators.

There was also participant feedback about applying ULC in contexts outside of the preservice course in which this study occurred. For instance, one participant stated, "I also 
think [ULC] is useful because the things we talked about we will encounter next year in student teaching and being able to go back and listen to the video will refresh our memories." Another participant stated, "I was able to utilize ULC as a teacher. I have used ULC on three other [educational] projects and become more comfortable with it." The application of ULC beyond the context of one course deepens learning with the new technology.

\section{Learning That Is Equitable and Social Justice Oriented}

The final domain of the TPDL framework (Darling-Hammond et al., 2018) focuses on how learning develops skills to assess students' needs, to reach all students, and to teach them well. It links social justice values with principles of learning and development by explicitly working to ensure that all students are supported, taking a critical stance, and avoiding deficit thinking.

The qualitative data revealed that participants valued ULC as a method for promoting social justice within their classrooms. However, many participants also highlighted the lack of technology in many of their K-12 school sites, which they saw as a drawback to using ULC, despite the fact that ULC only requires one iPad for teacher use. For instance, one preservice teacher participant stated:

We talked about how technology can make the classroom a fairer environment for all students to learn in; fair does not always mean equal. This is an important concept to know and to also see that technology can be used in different ways to help students.

Furthermore, another participant connected self-reflection to culturally responsive teaching practice, noting, "I could see myself listening to my own lecture to see how clear and concise I am. Do I show any biases that I am not aware of?" These questions about bias and access to technology help promote social awareness among pre-service teachers who will likely work in diverse classrooms. Finally, one pre-service participant highlighted the environmental benefits of ULC, a social justice cause that is often overlooked in teacher preparation programs:

ULC is also a great tool to keep your classroom organized and paperless. There are so many papers and files that are involved in lesson plans and ULC allows teachers to keep all of their content resources in one virtual space. Students need to only click the lesson link to gain access to a plethora of resources and content information. ULC also may be seen as more environmentally friendly because teachers can add notes to the online presentation during the lecture, rather than provide each student with an individual paper handout.

Finally, as one participant commented, ULC also appeared to reduce student learner anxiety, especially when the new technology was modeled by the instructor: 
On the first day of [the course], [the] Professor exclaimed, 'We are going to be learning this (ULC) together.' I want to apply this motto when I use technology in my class but also want to apply this motto to my classroom in general. The teacher can be a researcher and can learn alongside their students.

It appeared that having the professor model the technology, in addition to classmates using the technology in class presentations, helped to decrease the stress of trying something new. This apprenticeship model is supported by situated learning theory (McLellan, 1996). Overall, social justice, especially related to technology access and culturally responsive teaching, appeared to be present with preservice teachers, representing the potential for deeper learning related to ULC.

\section{Discussion}

Overall, it appears that ULC benefitted preservice teacher educators, both as students and as future educators, and potentially deepened their learning in all four domains of the Teacher Preparation for Deeper Learning (TPDL) framework (Darling-Hammond et al., 2018). The preservice teacher candidates expressed excitement in using technology and an open-minded attitude toward trying new technologies. Additionally, ULC appears to be an engaging and interactive technology that aided student learning. This increased confidence through the applied use of technology in conjunction with content knowledge was also found in prior research (i.e., Abbitt, 2011). ULC made learning easier for preservice educators, and they identified benefits for their future students, including reviewing content, engaging with course content following absenteeism, and working at their own pace.

\section{Integration of TPACK}

The findings from this study demonstrate that modeling a new technology with preservice teacher educators can improve their confidence and potentially increase the likelihood of using new technologies in their teaching practice. This modeling and apprenticeship model for learning is supported by the TPACK Model (Koehler \& Mishra, 2009; Mishra \& Koehler, 2006). Preservice teachers were able to integrate their prior and scaffolded knowledge of content, pedagogy, and technology in a safe learning space that enhanced learning and confidence over time. This scaffolded integration is supported in prior research on TPACK (e.g., Abbitt, 2011; Graham, 2011; Koehler \& Mishra, 2009). This study supports the strategy of hands-on, authentic practice for preservice teachers experienced when introducing a new instructional technology (Lave \& Wenger, 1990). This research demonstrates the positive impact on preservice teacher confidence and learning potential when engaging with new technologies in the midst of content learning and modeling from the instructor. 


\section{Challenges with ULC}

Despite the positive feedback from both the qualitative and quantitative data regarding ULC, the experience of using this new and innovative technology was not without challenges. The biggest challenges associated with the implementation of ULC included anxiety regarding using a new technology publicly and the vulnerability that accompanies that experience. Words that surfaced in the qualitative data included frustrated, nervous, foreign, weird, self-conscious, nerve-racking, and pressure. However, preservice teachers recognized the value of a teacher learning alongside students. For instance, one participant said:

Before this class, I was hesitant to use technology and didn't know if I would make it a priority to integrate it into my classroom if I wasn't confident in using it. However, the main take away this course taught me is you don't need to be an expert to try something in the classroom.

Despite the mentorship, modeling, and scaffolding learning around a new technology, student anxiety was still present and needs to be considered when asking preservice teachers to be vulnerable and try something new.

\section{Recommendations for ULC Use with Preservice Teachers}

Based on the many forms of data analyzed for this study, several recommendations surfaced that can support teacher educators in using ULC for preservice teacher learning. First, it is recommended that the teacher educator model vulnerability in using a new technology and thus scaffold the learning for the students. The qualitative data support the cognitive apprenticeship and coaching model advocated in McLellan's (1996) situated learning theory. It appeared that the more students practiced with the technology in the classroom, the more confident and competent they became. For instance, one participant stated, "I need more practice, but I am ready to try a lot of new technology in my future classrooms." Another participant said they realized throughout the semester, "I don't have to be an expert to utilize technology." It appears that having multiple opportunities for practice, collaboration, and reflection (McLellan, 1996) did improve student learning regarding ULC.

It is also recommended that the teacher educator ensure a safe and inclusive learning environment that supports students' anxiety to use a new technology. Despite the confidence voiced in student feedback, the data also revealed a fear and vulnerability that students accepted and embraced as part of learning a new instructional technology. For instance, one participant stated: "I need more practice, but I am ready to try a lot of new technology in my future classrooms!" Another mentioned, "I learned I don't have to be an expert to utilize technology." This comment relates back to the TPACK (Koehler \& Mishra, 2009; Mishra \& Koehler, 2006) framework, which focuses on teachers' integration of pedagogy, content knowledge, and technological knowledge. 


\section{Conclusion}

As technology continues to advance at rapid rates, and teachers at all levels adjust to the impacts of COVID-19 on education, preservice teacher educators must commit to the vulnerability and challenge of trying new technologies within teacher preparation programs, where they can feel safe and supported in learning and applying something new. Providing opportunities for apprenticeship and coaching, practice, collaboration, and reflection (McLellan, 1996) can help prepare teachers who are confident and competent in integrating technology in their future digital classrooms. One participant provided a meaningful summary of these findings: "Rather than running from this technology, we need to embrace it and take the initiative to be technologically literate."

\section{Acknowledgments \& Declaration of Interest Statement}

Beyond professional development and a contribution to the field of Education, we have no personal benefits from this research.

\section{Funding}

This research did not receive any specific grant from funding agencies in the public, commercial, or not-for-profit sectors.

\section{Disclosure Statement}

The researchers in this study did not benefit monetarily from this research. 


\section{References}

Abbitt, J. T. (2011). An investigation of the relationship between self-efficacy beliefs about technology integration and technological pedagogical content knowledge (TPACK) among preservice teachers. Journal of Digital Learning in Teacher Education, 27(4), 134-143. doi: 10.1080/21532974.2011.10784670

Adams Becker, S., Freeman, A., Giesinger Hall, C., Cummins, M., and Yuhnke, B. (2016). NMC/CoSN Horizon Report: 2016 K-12 Edition. Austin, Texas: The New Media Consortium.

Aldunate, R., \& Nussbaum, M. (2013). Teacher adoption of technology. Computers in Human Behavior, 29(3), 519-524. doi:10.1016/j.chb.2012.10.017

Alger, C., \& Kopcha, T. (2009). eSupervision: A technology framework for the 21st century field experience in teacher education. Issues in Teacher Education, 18(2), $31-46$.

An, Y. J., \& Reigeluth, C. (2011). Creating technology-enhanced, learner-centered classrooms: K-12 teachers' beliefs, perceptions, barriers, and support needs. Journal of Digital Learning in Teacher Education, 28(2), 54-62. doi:10.1080/2153 2974.2011.10784681

Chesley, G. M., \& Jordan, J. (2012). What's missing from teacher prep? Educational Leadership, 69(8), 41-45.

Creswell, J. (2013). Qualitative inquiry and research design: Five different approaches. SAGE.

Darling-Hammond, L., Guha, R., Hyler, M., Oakes, J., \& Wojcikiewicz, S. (2018, April 17). Teacher preparation for deeper learning. Retrieved July 30, 2018 from the AERA Online Paper Repository.

Darling-Hammond, L., \& Oakes, J. (2019). Preparing teachers for deeper learning. Cambridge, MA: Harvard Education Press.

Dillman, D. A., Phelps, G., Tortora, R., Swift, K., Kohrell, J., Berck, J., \& Messer, B. L. (2009). Response rate and measurement differences in mixed-mode surveys using mail, telephone, interactive voice response (IVR) and the Internet. Social science research, 38(1), 1-18. https://doi.org/10.1016/j.ssresearch.2008.03.007

Foulger, T. S., Wetzel, K., \& Buss, R. R. (2019). Moving toward a technology infusion approach: Considerations for teacher preparation programs. Journal of Digital Learning in Teacher Education, 35(2), 79-91. https://doi.org/10.1080/21532974.2 $\underline{019.1568325}$ 
Gosper, M., McNeill, M., Woo, K., Phillips, R., Preston, G., \& Green, D. (2011). Webbased lecture technologies and learning and teaching: A study of change in four Australian universities. Journal of Asynchronous Learning Networks, 15(4), 8495. https://doi.org/10.1080/09687769.2010.529111

Graham, C. R. (2011). Theoretical considerations for understanding technological pedagogical content knowledge (TPACK). Computers \& Education, 57, 1953-1960. https://doi.org/10.1016/j.compedu.2011.04.010

Hammonds, L., Matherson, L., Wilson, E., \& Wright, V. (2013). Gateway tools: Five tools to allow teachers to overcome barriers to technology integration. Delta Kappa Gamma Bulletin, 80(1), 36-40.

Hicks, S. D. (2011). Technology in today's classroom: Are you a tech-savvy teacher? The Clearing House, 84, 188-191. https://doi.org/10.1080/00098655.2011.557406

Kim, C., Kim, M., Lee, C., Spector, J. M., \& DeMeester, K. (2013). Teacher beliefs and technology integration. Teaching and Teacher Education, 29, 76-85. doi:10.1016/j.tate.2012.08.005

Koehler, M. J., \& Mishra, P. (2009). What is technological pedagogical content knowledge? Contemporary Issues in Technology and Teacher Education, 9(1), 60-70. https://doi.org/10.1177/002205741319300303

Krautscheid, L., Williams, S., Kahn, B., \& Adams, K. (2019). Untethered lecture capture: A qualitative investigation of college student experiences. Journal of Educational Technology Systems, 48(1), 97-111. https://doi.org/10.1177/0047239519833690

Kurt, S. (2013). Creating technology-enriched classrooms: Implementational challenges in Turkish education. Learning, Media and Technology, 38(1), 1-17. doi:10.1080/ 17439884.2013.776077

International Society for Technology in Education. (2020). ISTE standards for educators. https://www.iste.org/standards/for-educators

Lave, J., \& Wenger, E. (1990). Situated learning: Legitimate peripheral participation. Cambridge, UK: Cambridge University Press.

Li, Y., \& Ranieri, M. (2010). Are "digital natives" really digitally competent? A study on Chinese teenagers. British Journal of Educational Technology, 41(6), 1029-1042. doi:10.1111/j.1467-8535.2009.01053.x

Marchand, J.P., Pearson, M., \& Albon, S. (2014). Student and faculty member perspectives on lecture capture in pharmacy education. American Journal of Pharmaceutical Education, 78(4), 74. https://doi.org/10.5688/ajpe78474 
McLellan, H. (1996). Situated learning: Multiple perspectives. In H. McLellan (Ed.), Situated learning perspectives (pp. 5-17). New Jersey: Educational Technology Publications.

Miles, M. B., Huberman, A. M., \& Saldaña, J. (2014). Qualitative data analysis: A methods sourcebook. (3rd ed.). Thousand Oaks, CA: Sage Publications, Inc.

Mishra, P., \& Koehler, M. J. (2006). Technological pedagogical content knowledge: A framework for teacher knowledge. Teachers College Record, 108(6), 1017-1054. https://doi.org/10.1111/j.1467-9620.2006.00684.x

Papanikolaou, K., Makri, K., \& Roussos, P. (2017). Learning design as a vehicle for developing TPACK in blended teacher training on technology enhanced learning. International Journal of Educational Technology in Higher Education, 14(1), 1-14. https://doi.org/10.1186/s41239-017-0072-z

Pham, H. H., \& Ho, T. T. H. (2020). Toward a 'new normal' with e-learning in Vietnamese higher education during the post COVID-19 pandemic. Higher Education Research \& Development, 39(7), 1327-1331. https://doi.org/10.1080/07294360.2020.1823945

Philipsen, B., Tondeur, J., Roblin, N. P., Vanslambrouck, S., \& Zhu, C. (2019). Improving teacher professional development for online and blended learning: A systematic meta-aggregative review. Educational Technology, Research and Development, 67, 1145-1174. https://doi-org.ezproxy-eres.up.edu/10.1007/s11423-019-09645-8

Pokhrel, S., \& Chhetri, R. (2021). A literature review on impact of COVID-19 pandemic on teaching and learning. Higher Education for the Future, 8(1), 133-141. https://doi.org/10.1177/2347631120983481

Wetzel, K., Buss, R., Foulger, T. S., \& Lindsey, L. (2014). Infusing educational technology in teaching methods courses: Successes and dilemmas. Journal of Digital Learning in Teacher Education, 30(3), 89-103. doi:10.1080/ 21532974.2014.891877 